\title{
INFLUENCE OF TYPE AND CONTENT OF FIBERS ON THE PERFORMANCE OF SELF-COMPACTING CONCRETE
}

\author{
BY \\ M.M Balaha \\ Lecturer Eng. Materials Dept., Faculty of Eng., Zagazig University, Zagazig, Egypt.
}

\begin{abstract}
Self-compacting concrete (SCC) is used to facilitate constructability and ensure proper filling and good structural performance of highly congested and complex design structural sections. It is also used to improve productivity of concrete placement and provide better working environment by eliminating the vibration noise. The use of fibers in SCC provides a way of increasing productivity as it combines the positive effects of eliminating vibration work.

The purpose of this study is to investigate the self-compactability of fresh concretes with different types of fibers (steel, glass and polypropylene fiber mesh) and different volumetric ratio of fibers $(0.0,0.5$ and $1 \%)$. In this paper, the self-compactability of fresh concretes with these types and different anounts of libers were investigated by means of the slump flow test, the V-type funnel test and L-box method. No compaction was used for the SCC mixes, while the reference mix was compacted using the vibrating table. Also, in this study, the mechanical properties of hardened self-compacting concrete (SCC) were investigated in terms of staudard compressive and splitting tensile strength

Results from these tests show that there may be a slight reduction in workability due to the addition of fibers. However despite the small reduction in workability it is generally not more difficult to produce a good SCC with fibers than without. The results indicate that it is possible to achieve a good SCC also with a rather large amount of fibers.
\end{abstract}

Manuscript received from Dr. M.M. Balaha

Accepted on : $25 / 9 / 2001$

Engineering Research Journal Vol 24,No 4, 2001 MinufiyaUniversity, Faculty of

Engineering, Shebien El-Kom, Egypt, ISSN 1110-1180 
Self-compacting concrete (SCC) is highly flowable concrete that can spreau miv pacu under its own weight and achieve good consolidation without internal or external vibration and without exhibiting defects due to segregation and bleeding. Self-compacting concrete is a product of technological advancement in the area of under-water concrete teclmology where the mixture is proportioned to ensure ligh fluidity while providing high resistance to water dilution and segregation. The use of SCC has gained wide acceptance in Japan since the late 1980's for casting congested members as well as well as the placement of concrete in restricted areas where consolidation may not be practical [1-5]. In general, SCC is used to facilitate the filling of congested structural sections and cast elements with restricted access for placement and consolidation. For example, the repair of the bottom sides of beams, girders, and stabs often necessitates filling narrow and difficult to access areas. Self-compacting concrete can also be used in casting non-congested structures where limitation of concrete consolidation or the required duration of intervention can reduce coustruction costs as well as noise, which can be important in some urban areas. The use of Self-compacting concrete SCC for concrete structures promises to bring a number of advantages including reduced noise (resulting from vibration compaction), man power savings, and improved product quality [6-7].

The use of steel fiber reinforced concrete (SFRC] also gives an increase of potential productivity on site of ready mixed concrete due to the fact that some or all of the couventional re-bars or mesh can be excluded [8-9]. The incorporation of steel fibers improves engineering performance of structural and non-structural concrete, including better crack resistance, ductility and toughness, as well as greater tensile strength, resistance to fatigue, impact, blast loading, and abrasion. The incorporation of metallic fibers enhances the structural performance of reinforced concrete, including the reduction of spalling of the cover over reinforcement in column elements, the increase in shear strength of beams, as well as the enhancement of ductility of beam column connections. The fiber content, length, aspect ratio, and shape play an important role in controlling workability of FRC [10-11].

A truly fiber-reinforced SCC should spread into place under its own weight and achieve consolidation without internal or extemal vibration, ensure proper dispersion of fibers and undergo minimum entrapment of air voids and loss of homogeneity until hardening. Lack of proper self-consolidation or intentional vibration and compaction can result in macro-and micro-structural defects that can affect mechanical performance and durability. Typically, the reduction in fiber length and the decrease in the nominal size of aggregate and aggregate volume reduce such intemal resistance to flow aud increase workability. Providing proper resistance to bleeding and segregation is essential for the successful production and casting of SCC, especially when relatively heavy metallic fibers are incorporated [12-13].

The objectives of the study reported in this paper are to further establish the feasibility of producing and testing fiber self-compacting concrete (FSCC) and evaluate the suitability of evaluating restricted deformability of FSCC using workability tests proven. In this Investigation the properties of FSCC in the fresh and hardened state were discussed taking into consideration the effect of types of fibers (steel, glass and polypropylene fiber mesh) and different volumetric ratios of fibers $(0.0,0.5$ and $1 \%)$. 


\section{EXPERLMENTAL INVESTIGATION}

Twenty-seven self-compacting concrete (SCC) mixtures were prepared for different types and different volumetric ratios of fibers as shown in Table 1.

Table 1: Layout of Used Mixes.

\begin{tabular}{|c|c|c|c|c|c|c|c|}
\hline \multirow{2}{*}{$\begin{array}{l}\text { Mix } \\
\text { No. }\end{array}$} & \multicolumn{3}{|c|}{ Type of Fibers } & \multicolumn{3}{|c|}{$\%$ Volume Fraction of Fibers } & \multirow[t]{2}{*}{ Type of Test } \\
\hline & Steel & Glass & Polypropylene & 0 & 0.5 & 1 & \\
\hline 1 & $\sqrt{ }$ & & & $\sqrt{ }$ & & & \multirow{9}{*}{$\begin{array}{c}\text { Slump Flow } \\
\text { Test } \\
\text { (Slump Cone) }\end{array}$} \\
\hline 2 & $\sqrt{ }$ & & & $\cdots$ & & & \\
\hline 3 & $\sqrt{ }$ & & & 4 & & $\sqrt{ }$ & \\
\hline 4 & & $\sqrt{ }$ & & $\sqrt{ }$ & & & \\
\hline 5 & & $\sqrt{ }$ & & & $\sqrt{ }$ & & \\
\hline 6 & & $\sqrt{ }$ & & . & & $\sqrt{ }$ & \\
\hline 7 & & & $\sqrt{ }$ & $\sqrt{ }$ & & & \\
\hline 8 & & & $\sqrt{ }$ & & $\sqrt{ }$ & & \\
\hline 9 & & & $\sqrt{ }$ & & & $\sqrt{ }$ & \\
\hline 10 & $\sqrt{ }$ & & & $\sqrt{ }$ & & & \multirow{9}{*}{$\begin{array}{c}\text { Flow Time } \\
\text { Test } \\
\text { (V-Funnel) }\end{array}$} \\
\hline 11 & $\sqrt{ }$ & & & & $\sqrt{ }$ & & \\
\hline 12 & $\sqrt{ }$ & & & & & $\sqrt{ }$ & \\
\hline 13 & & $\sqrt{ }$ & & $\sqrt{ }$ & & & \\
\hline 14 & & $\sqrt{ }$ & & & $\sqrt{ }$ & & \\
\hline 15 & & $\sqrt{ }$ & & . & & $\sqrt{ }$ & \\
\hline 16 & & & $\checkmark$ & $\sqrt{ }$ & & & \\
\hline 17 & & & $\sqrt{ }$ & & $\sqrt{ }$ & & \\
\hline 18 & & & $\sqrt{ }$ & & & $\sqrt{ }$ & \\
\hline 19 & $\sqrt{ }$ & & & $\sqrt{ }$ & & & \multirow{9}{*}{$\begin{array}{c}\text { L-Box } \\
\text { Test }\end{array}$} \\
\hline 20 & $\sqrt{ }$ & & & & $\sqrt{ }$ & & \\
\hline 21 & $\sqrt{ }$ & & & & & $\sqrt{ }$ & \\
\hline 22 & & $\sqrt{ }$ & & $\sqrt{ }$ & & & \\
\hline 23 & & $\sqrt{ }$ & & & $\sqrt{ }$ & & \\
\hline 24 & & $\sqrt{ }$ & & & & $\sqrt{ }$ & \\
\hline 25 & & & $\sqrt{ }$ & $\sqrt{ }$ & & & \\
\hline 26 & & & $\sqrt{ }$ & & $\sqrt{ }$ & & \\
\hline 27 & & & $\sqrt{ }$ & & & $\sqrt{ }$ & \\
\hline
\end{tabular}

\section{Matcrials}

The mixtures were prepared with well-graded quartzite sand with a specific gravity of 2.69 , an absorption value of $1.2 \%$, and fineness modulus of 2.56 . Coarse aggregate gravel with a nominal size of $20 \mathrm{~mm}$ was used. It has a specific gravity of 2.79 and an absorption value of $0.77 \%$. Ordinary Portland Cement (OPC) from Suez factory was used and complied with the Egyptian Codc. The cement content and water cement ratio have been kept constant at 450 $\mathrm{kg} / \mathrm{m}^{3}$ and 0.4 , respectively. Clean tap water free from impurities was used for mixing the 
been used in order to allow deformability without segregation. The dosage of the viscosityenhanced admixture (VEA) used in this work was $1.5 \%$ of cement weight. A continuously deformed shape stainless steel fiber was used. The steel and glass fiber length of $25 \mathrm{~mm}$ was selected. Polypropylene fibers manufactured by fiber mesh Co. Division of synthetic industries in USA wilh $25 \mathrm{~mm}$ length, 0.9 specific gravity and young's modulus of $3.5 \mathrm{KN} / \mathrm{mm}^{2}$ were used. A high range water reducing agent (HRWR) (sulfonated naphthalene formaldeliyde base, SNF) was added in the amount of $3 \%$ by weight of the cement. The absolute volume method recommended by $\mathrm{ACI}$ committee was used to determine the required quantities of materials for the test mix. The volume of coarse aggregate was $50 \%$ of the total volume of solids in concrete. $\Lambda$ total 27 cubes, $15 \times 15 \times 15 \mathrm{~cm}$ and cylinders, $15 \mathrm{~cm}$ in diameter and $30 \mathrm{~cm}$ in length were casted and tested to determine compressive and tensile strengths of self-compacting concrete $(\mathrm{SCC})$ respectively.

\section{Testing Methods}

The used sand and coarse aggregate were washed by water to remove any impurities and clay and kept at room temperature one day before testing. To prepare the mixes, the dry constituents of cement and both coarse and fine aggregate were placed in the mixer and mixed for 60 seconds; then water containing the superplasticizer and VEA were added and mixing continued for a further four minutes. During this time, the different types of fibers were added to the mix. The properties of SCC in fresh state were determined by different methods such as slump flow, V-funnel and L-box method and by slump cone for ordinary concrete.

Slump-flow test: The slump flow is a method to test the workability by using the normal slump cone without compaction. The size of slump cone used (upper diameter of 100 $\mathrm{mm}$, lower diameter of $200 \mathrm{~mm}$ and height of $300 \mathrm{~mm}$ ) was regulated in JIS A 1101, and test was conducted in accordance with the guidelines of JSCE [14]. The slump cone is slowly lifted up vertically, and the diameter, which represents the maximum spread of the concrete, is measured as well as a diameter perpendicular to it. The average of these diameters was calculated to determine the slump flow value. Simultaneously with the slump flow test, measurement of the time taken by slump flow to reach a $500 \mathrm{~mm}$ value was done and naked eye observation on segregation was also performed. This test also clearly verifies the stability of the concrete.

$L$-box method: The L-box was made in the workshop with dimensions as shown in Fig. 1 and Photo. 1. The test is set up by filling the vertical part of the L-flow apparatus concrete without any consolidation. The gate separating the vertical and horizontal parts is then lifted enabling the concrete to spread into the horizontal section. The end of the horizontal section is removed to enable the concrete to spread for a distance greater than $150 \mathrm{~cm}$, if necessary. The maximum spread distance form the vertical gate $\left(\mathrm{L}_{\max }\right)$ is measured to assess the deformability capacity of the concrete. Similarly, the velocity of the concrete spread at various stations (40, 60 and $80 \mathrm{~cm}$ from the gate) can be detcrmined to assess the speed of deformability. The average surface gradient $(\mathrm{H} / \mathrm{L})$ can be calculated to evaluate the self-leveling property of the concrete. Such value is taken as the ratio of the difference in concrete heights determined at a distance of $10 \mathrm{~cm}$ away from the gate and at the end of the spread out concrete divided by $\left(\mathrm{L}_{\max }-10 \mathrm{~cm}\right)$. 
V-type funnel test: $\mathrm{V}$ type funnel test was conducted using a funnel with the shape and dimensions shown in Photo. 2 and Fig. 2. The fresh concrete was placed in the fumel without any compaction, and the bottom of the fumel was opened allowing the concrete to flow down. The time taken by the fresh concrete to flow out of the funnel was measured [15].

\section{TEST RESULTS AND DISCUSSION}

The slump flow test was chosen to study the free deformability of the SCC, while the V-fumnel flows were employed to evaluate the restricted deformability. The V-funnel test was employed to assess the feasibility of aggregate particles and mortar to change their flow paths and spread through a restricted area without blockage. The measured values (in seconds) $\mathbf{T}_{40}$, $T_{60}$ and $T_{80}$ were obtained to measure the velocity of SCC. These values describe the viscosity of the SCC in the way that longer measured velocity corresponds to higher viscosity. These tests were carried out to obtain the properties of fresh concrete. Various mixes of SCC were prepared for different types of fibers (steel, glass and polypropylene fiber mesh) and different volumetric ratios of fibers $(0.0,0.5$ and $1 \%)$.

\section{Effect of Types of Fibers on Properties of Fresh SCC}

The effect of types of fibers measured by the slump flow test with different volumetric ratios of fibers is clearly shown in Fig. (3). This figure shows that the addition of steel fibers had the maximum efrect on the slump flow diameter of SCC. The degree of workability reduction due to fiber addition is lower in the case of the polypropylene fiber concrete than the glass fiber mixture. For example when adding polypropylene fibers to SCC, the slump flow diameter was decreased by about $5 \%$ than the glass fiber mixture and decreased by about $7 \%$ than the steel fiber mixture. These results were obtained when volume fraction of fibers was $0.5 \%$. This behavior may be explained as follows: The presence of steel fibers in SCC allows fibers to be distributed over the whole area of SCC during the mixing more than the other types of fibers, which leads to a high fluidity of self-compacting concrete. It is believed that the rigidity of the steel fibers in comparison to the other two types is responsible for the better performance of these steel fibers. The other two types of fibers have the tendency to interfere together, in some places in the mix, which results in reduction in the workability and deformability of the mix. It is generally not more difficult to produce a good SCC with the addition of glass or polypropylene fibers. Test results presented in Fig. (4) show the time required for the concrete to reach a diameter of $500 \mathrm{~mm}$ on the flowing table $\left(\mathrm{T}_{50}\right)$ for different types and volume fractions of fibers. When using polypropylene fibers for casting the concrete, the slump flow time, $T_{50}$ was not observed and measured. The workability for this type of fibers was low but still considerably greater than that of the reference mix. It can be concluded that the incorporation of steel fibers to $\mathrm{SCC}$ can then increase the slump flow time $\left(\mathrm{T}_{50}\right)$.

Figure (5) explains the effect of types of fibers on the V-funnel flow time of SCC for different volumetric ratios of fibers. It can be noticed that the flow time was increased for the addition of polypropylene fibers to SCC than for the addition of glass or stecl fibers to SCC. As an example, the V-funnel flow time was decreased by about $13 \%$ for SCC made by glass fibers in comparison to concrete made by polypropylene fibers, and was decreased by about $36 \%$ for incorporation of steel fibers rather than polypropylene fibers mesh. These results were reported when the volumetric ratio of fibers was $0.5 \%$. 


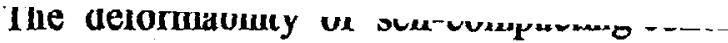

of SCC passing in the $L$-box method corresponding to $T_{40}, T_{60}$ and $T_{80}$ for different types and volumetric ratios of fibers as shown in Fig. (6). This figure indicates that the velocity of SCC was increased by about $45 \%$ more for the addition of steel fibers than when using polypropylene fibers. Figure (7) was employed to evaluate the $\mathrm{H} / \mathrm{L}$ ratio of $\mathrm{SCC}$ for different types and volume fractions of fibers. When $\mathrm{H} / \mathrm{L}$ ratios were decreased, this meanthigher defornability and flowability of SCC were obtained. 'This figure reflects that the addition of steel fibers gives an excellent deformability and flowability of SCC.

\section{Effect of Volumetric Ratios of Fibers on Properties of Fresh SCC}

Figure (8) shows the decrease in slump flow diameter for different volumetric ratios and types of fibers. This figure indicates that the increase in fiber volume resulted in a net reduction in the slump flow diameter. For example, the increase in fiber volume from 0.0 to $0.5 \%$ resulted in a lower slump flow diameter by about $10 \%$, and when fiber volume increased from 0.5 to $1 \%$, this resulted in a lower slump flow diameter by about $9 \%$. These results were obtained when adding steel fibers to the SCC. Also, it can be noticed from Fig. (9) that the slump flow time $\left(\mathrm{T}_{50}\right)$ was increased for increasing volume fraction of fibers.

Test results presented in Fig. (10) gives the V-fumnel flow time for different volumetric ratios and types of fibers. This figure shows that increasing volume fraction from 0.0 to $0.5 \%$ resulted in increasing the V-funnel flow time by about $40 \%$ and when increasing volume fraction from 0.5 to $1 \%$, this resulted in increasing the V-fumnel flow time by about $50 \%$. These results were reported when adding steel fibers to SCC. This is because a high volume of fibers increases the intemal resistance to flow and intrinsic viscosity as well as the degree of fiber interference with flow through the restricted section of V-funuel test. Figure (11) illustrate the effect of volume fraction of fibers on the velocity of SCC for different types of fibers. It was observed that increasing volume fraction of fibers up to $1 \%$, the velocity of SCC was decreased by about $20 \%$ for the addition of steel fibers. High deformability was obtained when the fiber volume was limited to $0.5 \%$. At $1 \%$ fibers, the deformability was low but still considerably greater than that of the conventional mixture. Also it was found that as polypropylene fibers content increases from 0.0 to $0.5 \%$, the $\mathrm{H} / \mathrm{L}$ ratios were increased and reached to $10.5 \%$, and when polypropylene fibers content increases from 0.5 to $1 \%$ a significant increase in $\mathrm{H} / \mathrm{L}$ ratios was obtained and reached to $28 \%$ as shown in Fig. (12).

\section{The Mechanical Properties of SCC}

Figures (13 and 14) show the development of compressive and tensile strengths as a function of different types and volumetric ratios of fibers of SCC. These figures indicate that the addition of steel fibers to SCC resulted in slightly increases for both the compressive and tensile strengths in comparison to the other two types. Also, it was found that as the steel fibers content increases from 0.0 to $0.5 \%$ the compressive and tensile strength increased by about $4 \%$ and $14 \%$ respectively, and when fibers volume increased from 0.5 to $1 \%$, this resulted in a ligher the compressive and tensile strengths by about $6 \%$ and $11 \%$ respectively. The relatively higher in the compressive and tensile strengths of the SCC is believed to be mainly due to the inclusion no porosity was found in the SCC. Also fibers works as a crack closure where fibers are randomly distributed through the volume of the concrete at spacing very smaller. 


\section{CONCLUSIONS}

As a result of this investigation and the comparison of the SCC with the reference mix, the following conclusions may be drawn:

1. High deformability was obtained when the fiber volume was limited to $0.5 \%$. At $1 \%$ fibers, the deformability was low but still considerably greater than that of the conventional mixture.

2. The flow time of SCC became faster with the decrease of volume fraction of fibers.

3. V-funnel test sliould be used to assess workability and blockage resistance. This is especially important when the fiber volume increases causing greater hindrance of spreading.

4. It is possible to achieve a good SCC and a higher in the compressive and tensile strength with a rather large amount of fibers.

5. Self-compacting concrete (SCC) containing steel fibers exhibited higher deformability and flowability than those containing polypropylene or glass fibers.

\section{REFERENCES}

1. Khayat, K.I., and Manai, K., "Self-Leveling Concrete-Properties and Applicatious", (in French), Proceedings, Workshop on Self-Leveling Concrete, PP. 1-30, 1996.

2. Okamurea, H., "Self-Compacting Higlt-Performance Concrete", Proceedings, Concrete Intemational, Vol. 19, No. 7, PP. 50-54, July 1997.

3. Ozawa, K., Maekawa, K., and Okamura, H., "Development of the High Performance Concrete", Journal of the Faculty of Engineering, the University of Tokyo (B), XL1 (3) PP. $381-439,1992$.

4. Sakata, N., Marruyama, K., and Minami, M., "Basic Properties and Effects of Welan Gum on Self-Consolidating Concrete", RILEM Proceedings 32, Production Methods and Workability of Concrete, paisely, Ed. Bartos, P.J.M., Marrs, D.L. and Cleland, D.J., PP. 237-253, 1996.

5. A.G. Abdel-Kahman and M.M. Balaha, "Properties of Self Compacting Concrete in the Fresh State" Indian Journal of Engineering \& Materials Sciences, (communicated)

6. Ushijima, S., Harada, K, and Taniguchi, H., "Fundamental Study on the Practical Use of High Performance Concrete", Proceedings, Concrete Under Severe Conditions, Euviromment and Loadings, Sapporo, Japan, Ed. Sakai, K, Banthia, N. and Gjorv, O.E., 2, PP. 1005-1014, 1995.

7. Nagataki, S., Fujiwara, H., "Self-Compacting Properties of Highly Flowable Concrete", Proceedings of Second lnternational Symposium on Advances in Concrete Technology, SP 154-16, PP. 301-314, 1995.

8. Bayasi, M.Z. and Soroushian, P. "Effect of Steel Fiber Reinforcement on Fresh Mix Properties of Concrete", ACI Materials Jourual, V. 89, No. 4, PP. 369-374, 1992.

9. Gustafsson, J. "Experience from Full Scale Production of Steel Fibre Reinforced SelfCompacting Concrete", RILEM Symposium on Self-Compacting Concrete, Stockholm, Sweden, 1999.

10. Balaguru, P. and Shah, S. "Fiber Reinforced Cement Composites", McGraw-Hill, 1991.

11. "ACI Manual of Concrete Practice Part 5", American Concrete Institute, 1993.

12. Yang, C.A., Cheru, J.C. and Miao, B., "Effect of Steel Fibers Content on Properties of High Performance Concrete", in High-Performance Concrete, ACI International Conference, Malaysia, 1997. 
13. Roy, C., "High-Performance Fiber-Kelmorcea sen-cunsumuans _......., Report, University de Sherbrocke, Dec. 1996.

14. JSCE, Guideline on Making Self-Compacting Concrete, Concrete Library 93, 1998.

15. Ozawa, K., Sakata, N. and Okanura, H., "Evaluation of Self-Compacting of Fresh Concrete Using the Funnel 'Test", Proceedings, Japan Society of Civil Eng., PP. 59-75, 1995. 

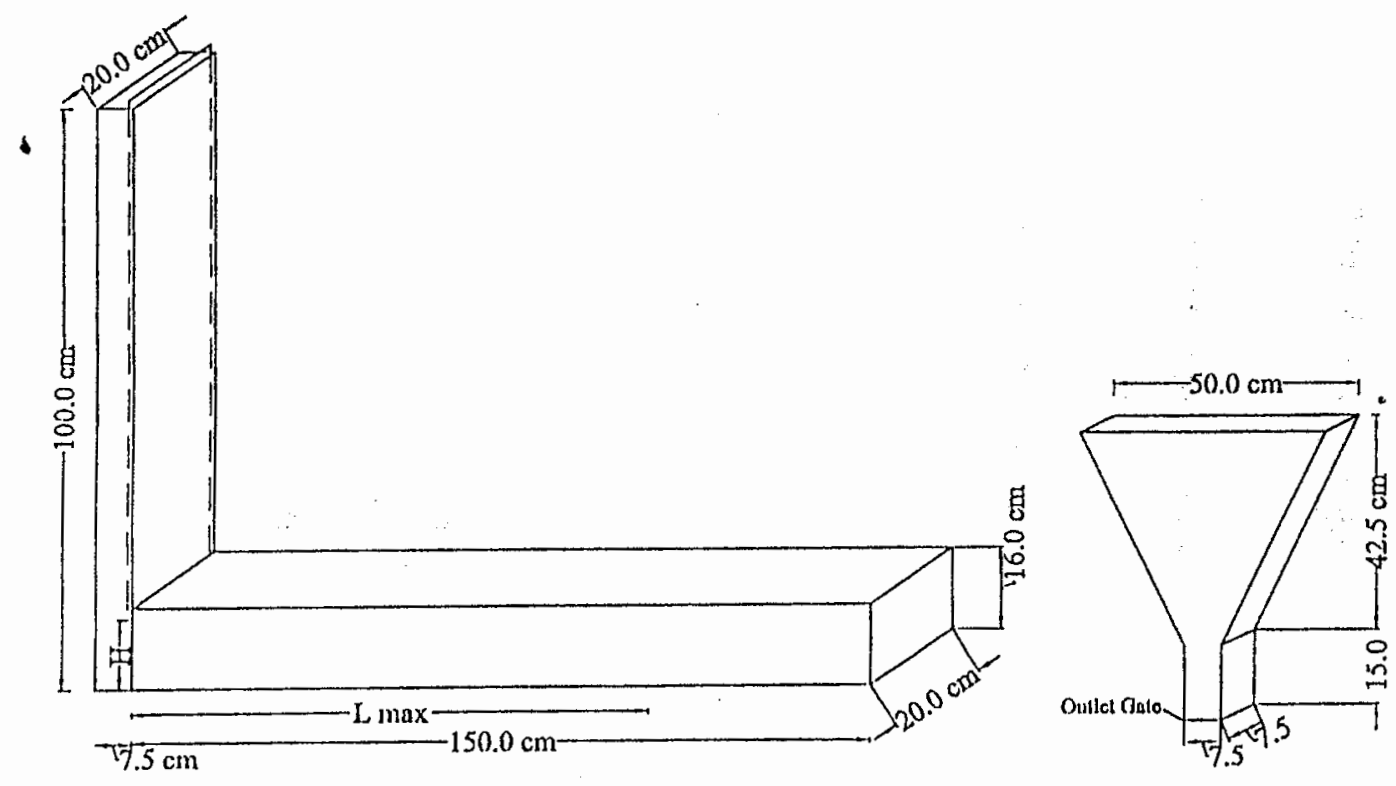

Fig. (1): Schematic of the L-Flow Deformability Test.

Fig. (2): Dimension of V-Funncl' : it.

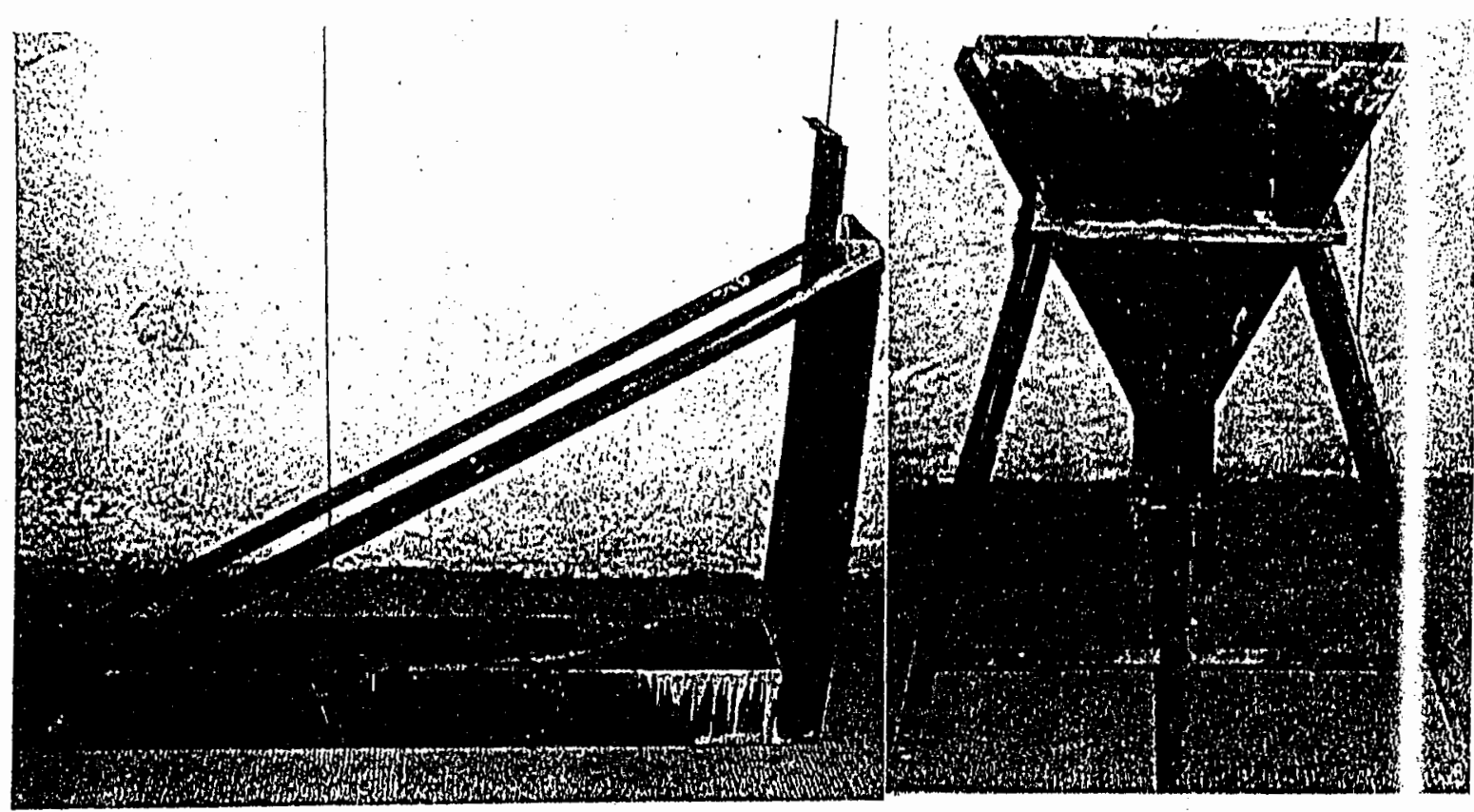

Photo. (1): L-box test.

Photo. (2): V-funnel test. 


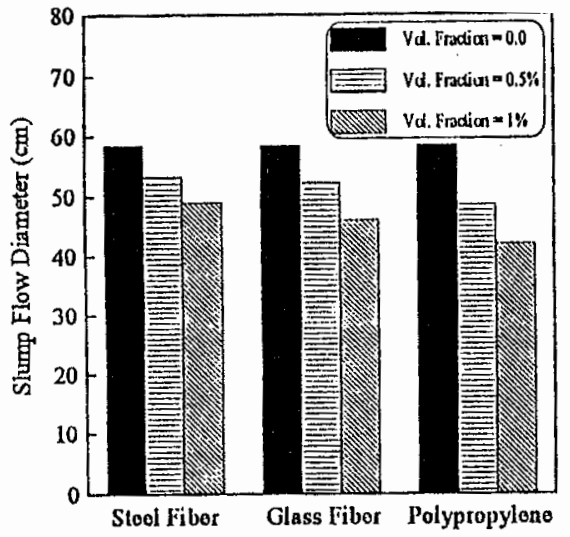

Fig. (3): Slump Flow Diancler versus Types of Fibers.

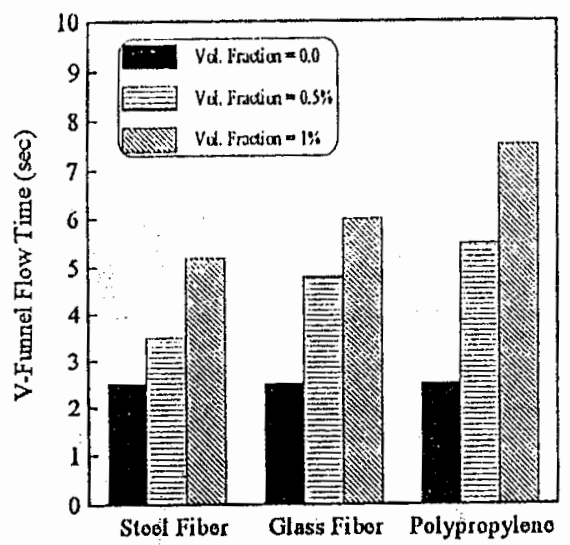

Fig. (5): V-Funnel Flow Tine versus Types of Fibers.

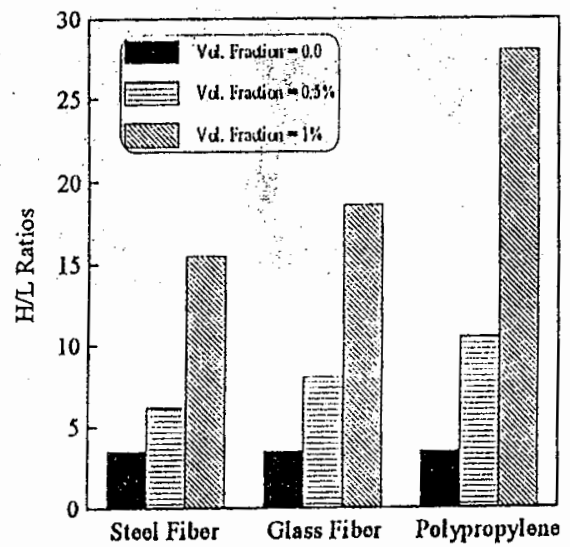

Fig. (7): H/L Ratios versus Types of Fibers.

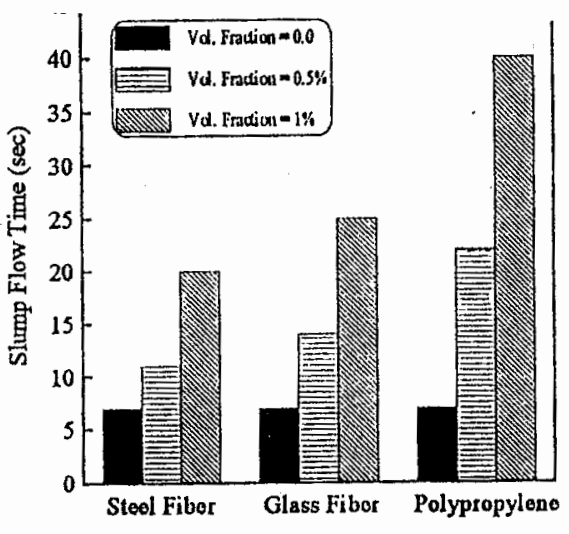

Fig. (4): Slump Flow Time versus Types of Fibers.

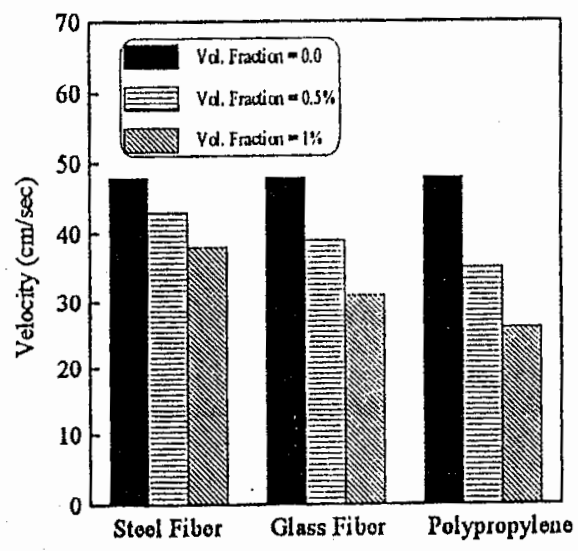

Fig. (6): Velocity of SCC versus Types of Fibers.

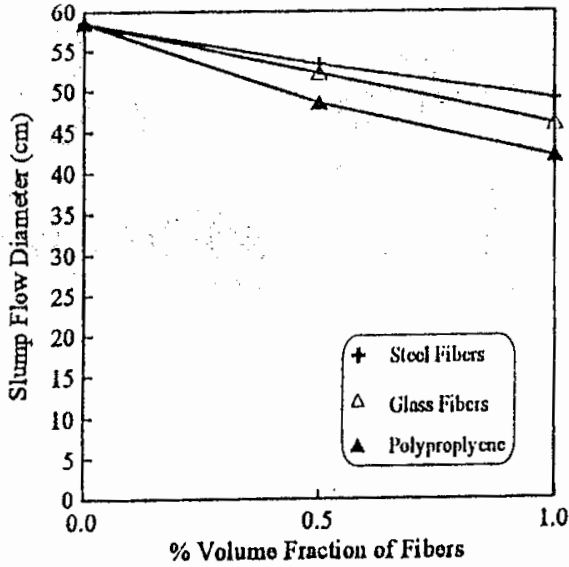

Fig. (8): Slump Flow Diancter versus Volume Fraction of Fibers 


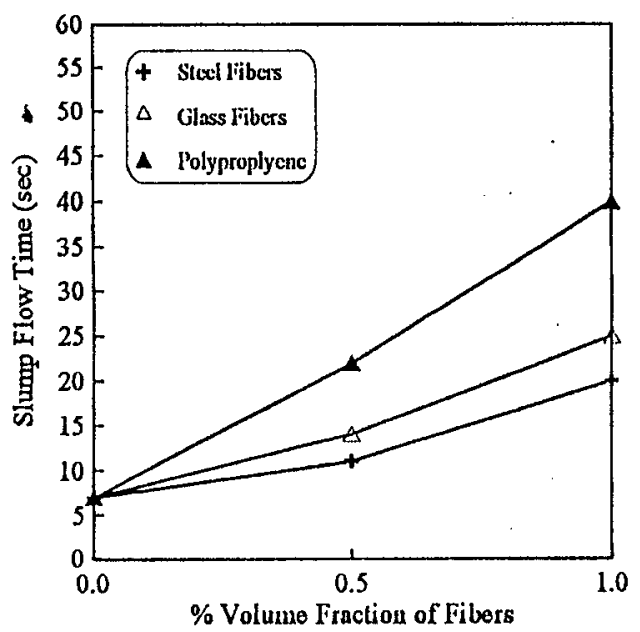

Fig. (9): Slump Flow Time versus Volume Fraction of Fibers

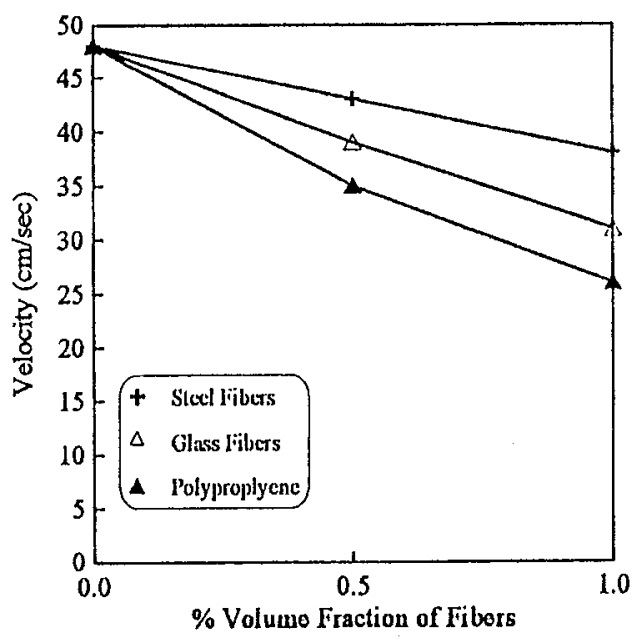

Fig. (11): Velocity of SCC versus Volume Fraction of Fibers

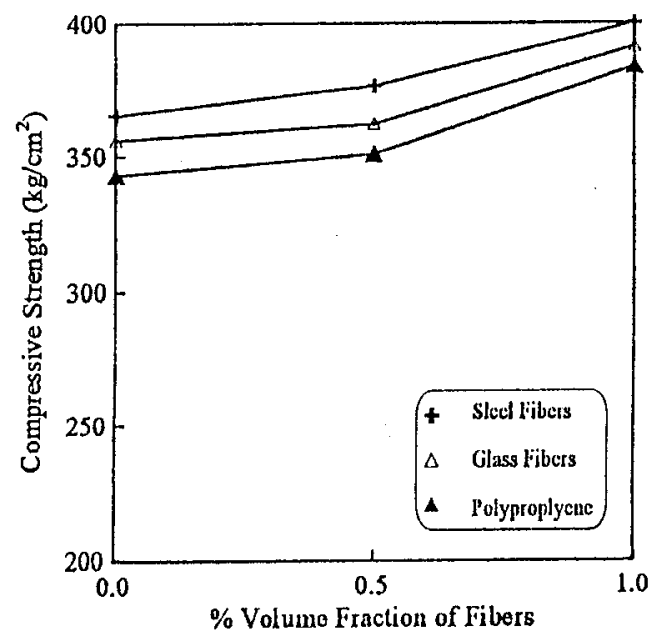

Fig. (13): Compressive Strength vs \% Volume Fraction of Fibers.

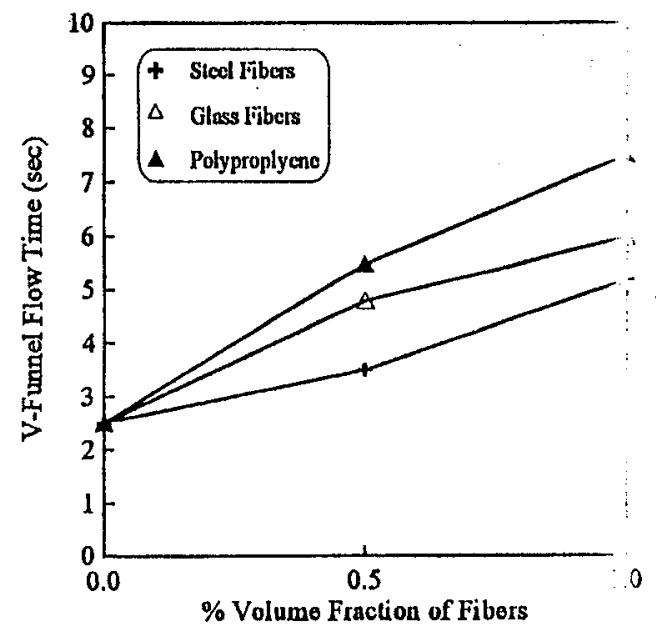

Fig. (10): V-Funnel Flow Time versus Volut. e Fraction of Fibers

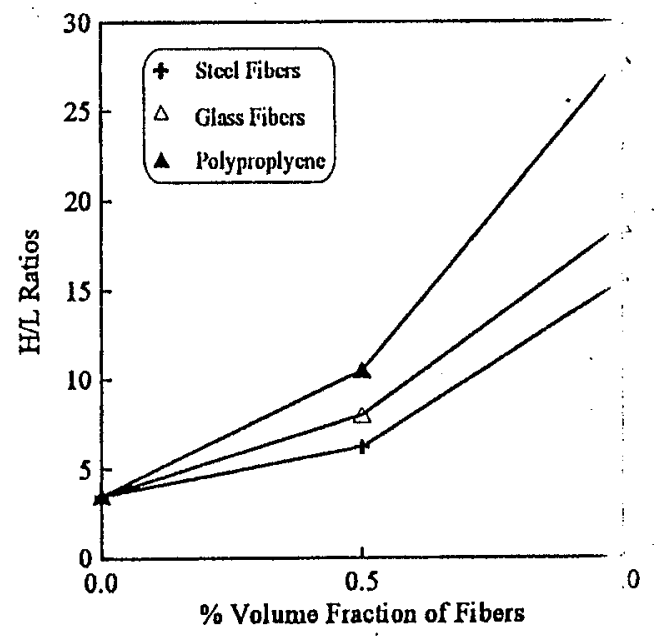

Fig. (12): $H / L$ Ratios versus Volume Fraction of Fibers.

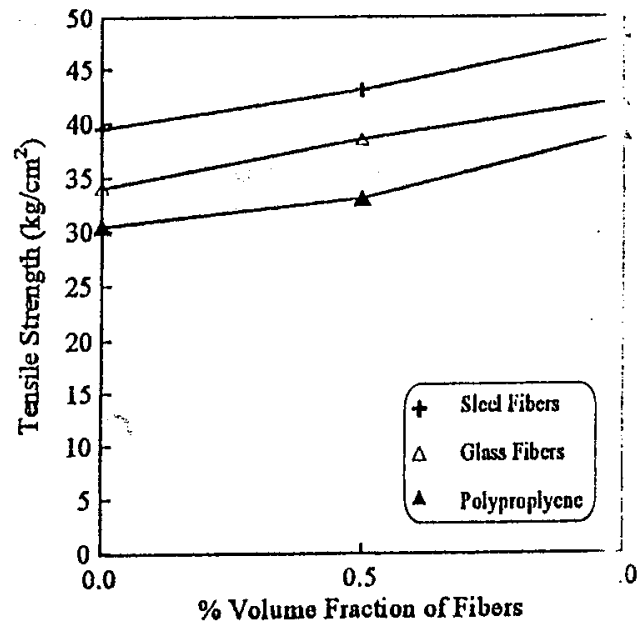

Fig. (14): Tensile Strength vs \% Volume Fractic . of Fibers. 


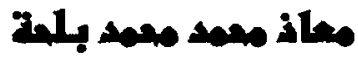

هدرس

كلية الهنسة - ثسم هندسة المواد - جامعة الزقازيق - الزقازيق - جمهوربة مصر العربية

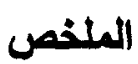

تعتبر الخرسانة ذاتية الدمك نوعية جديدة ذات أداء متعيز حيث تحتّ انسيابية عالية ولزوجة معتدلة للحصـول

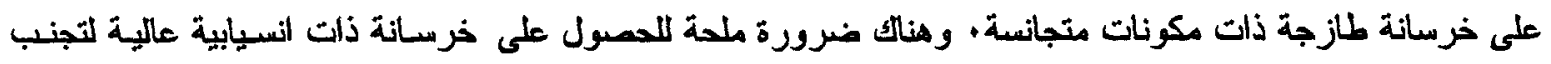

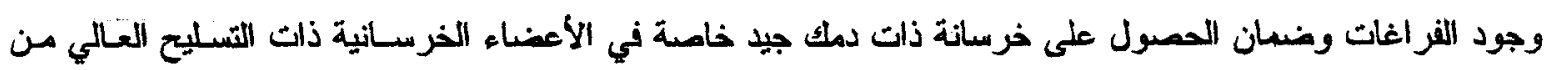

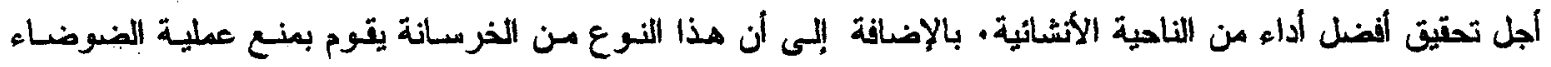

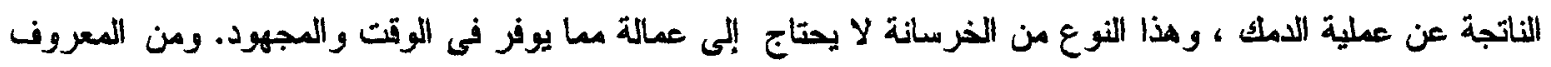

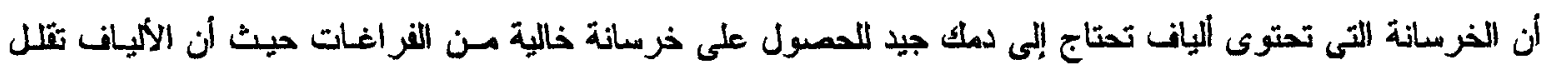

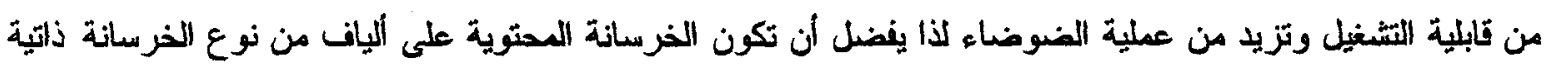

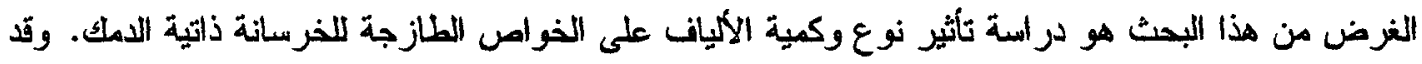

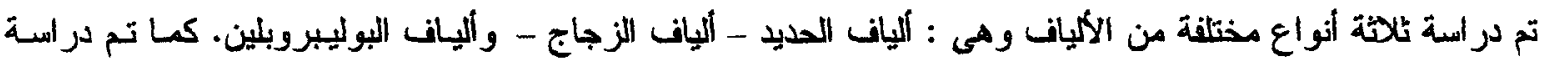

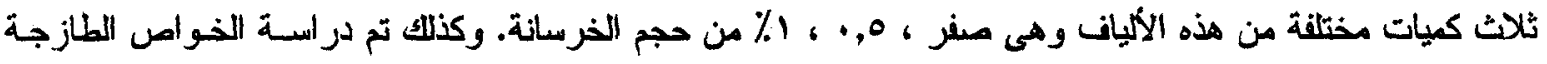

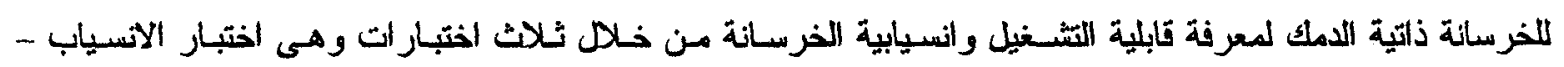

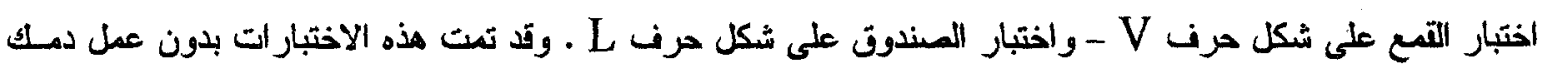

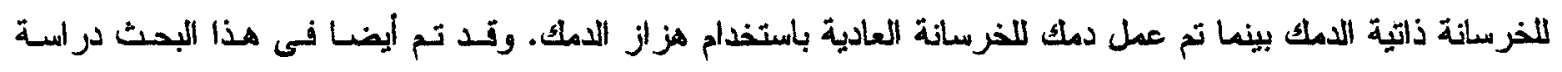

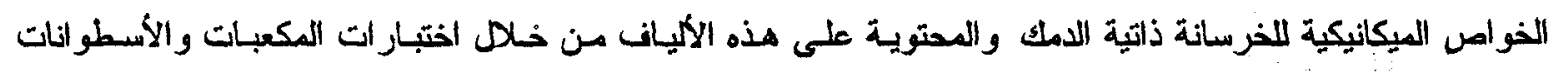

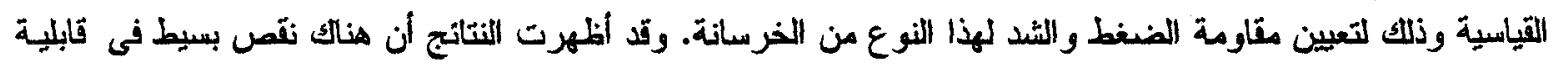

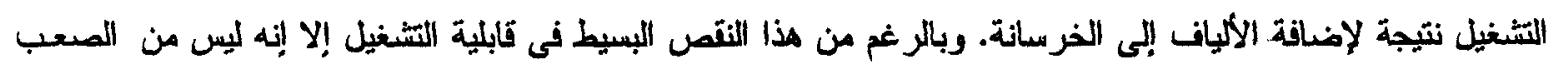

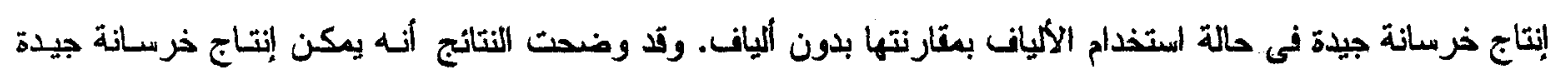

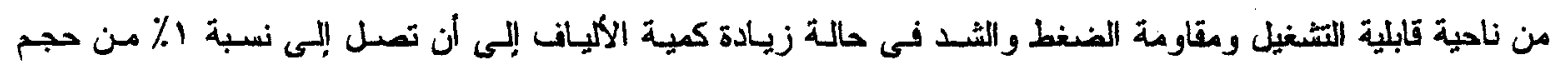

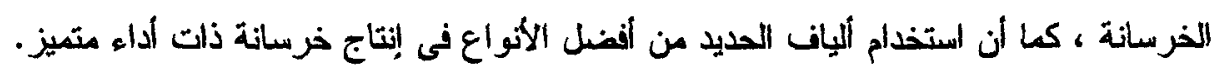

